\title{
ASO Visual Abstract: Effects of Adjuvant Endocrine Therapy Adherence and Radiation on Recurrence and Survival Among Older Women With Early-Stage Breast Cancer
}

\author{
Shayna L. Showalter, MD ${ }^{1}$, Max O. Meneveau, MD $^{1}$ (D), Jessica Keim-Malpass, RN PhD ${ }^{2}$, \\ T. Fabian Camacho, $\mathrm{MS}^{3}$, Gabriella Squeo, $\mathrm{MD}^{1}$, and Roger T. Anderson, $\mathrm{PhD}^{3}$ \\ ${ }^{1}$ Department of Surgery, Division of Surgical Oncology, University of Virginia School of Medicine, Charlottesville, VA; \\ ${ }^{2}$ University of Virginia School of Nursing, Charlottesville, VA; ${ }^{3}$ Department of Public Health Sciences, University of \\ Virginia School of Medicine, Charlottesville, VA
}

Women older than 70 years with early-stage breast cancer can omit radiation and be treated with breast-conserving surgery and adjuvant endocrine therapy alone (https://doi.org/10.1245/s10434-021-10064-4). However, adherence to adjuvant endocrine therapy is low in this population. This study demonstrated that recurrence is higher among women who omitted radiation and were not adherent to endocrine therapy.

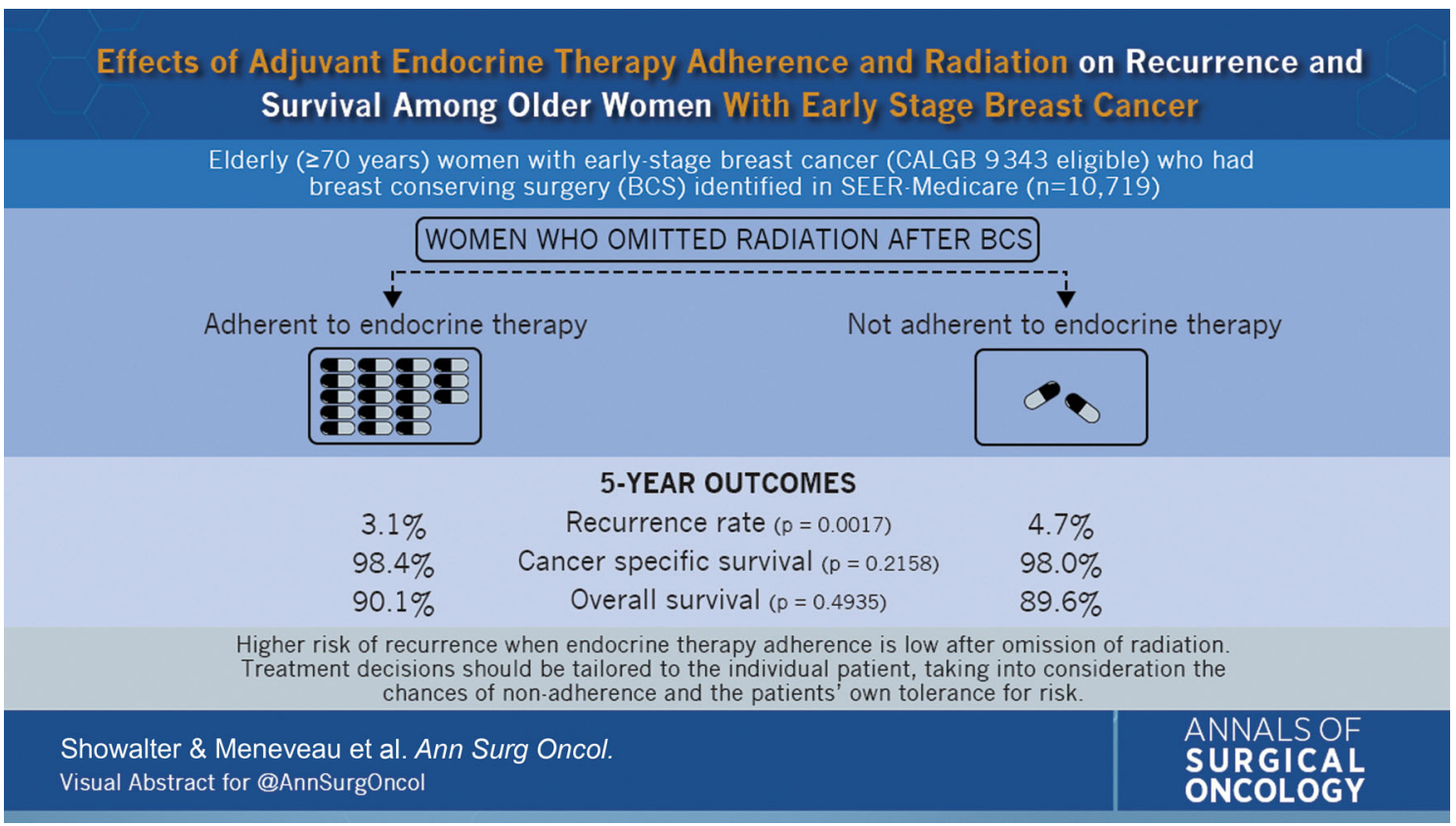

Shayna L. Showalter and Max O. Meneveau are joint first authors.

(C) Society of Surgical Oncology 2021

Publisher's Note Springer Nature remains neutral with regard to Published Online: 14 May 2021

jurisdictional claims in published maps and institutional affiliations.

S. L. Showalter, MD

e-mail: snl2t@virignia.edu 